\title{
XRD Investigation of Some Thermal Degraded Starch Based Materials
}

\author{
Mihai Todica, ${ }^{1}$ Elena Mihaela Nagy, ${ }^{2}$ Carmen Niculaescu, ${ }^{1}$ Oana Stan, ${ }^{1}$ \\ Nicolae Cioica, ${ }^{2}$ and Cornel Viorel Pop ${ }^{1}$ \\ ${ }^{1}$ Faculty of Physics, Babes-Bolyai University, Nr. 1, Kogalniceanu Str., 40047 Cluj-Napoca, Romania \\ ${ }^{2}$ INMA Bucharest, Branch Cluj-Napoca, Nr. 59, Al. Vaida Voievod Str., 40047 Cluj-Napoca, Romania
}

Correspondence should be addressed to Mihai Todica; mihai.todica@phys.ubbcluj.ro

Received 17 August 2016; Revised 24 October 2016; Accepted 10 November 2016

Academic Editor: Nikša Krstulović

Copyright (C) 2016 Mihai Todica et al. This is an open access article distributed under the Creative Commons Attribution License, which permits unrestricted use, distribution, and reproduction in any medium, provided the original work is properly cited.

\begin{abstract}
The thermal degradation of some starch based materials was investigated using XRD method. The samples were obtained by thermal extrusion of mixtures of different proportions of starch, glycerol, and water. Such materials are suitable for the manufacturing of low pollutant packaging. Thermal degradation is one of the simplest ways to destroy such materials and this process is followed by structural modification of the local ordering of samples, water evaporation, crystallization, oxidation, or destruction of the chemical bonds. These modifications need to be studied in order to reduce to the minimum production of pollutant residues by burning process. XRD measurements show modification of the local ordering of the starch molecules depending on the temperature and initial composition of the samples. The molecular ordering perturbation is more pronounced in samples with low content of starch.
\end{abstract}

\section{Introduction}

The recycling or disposal without pollutant effects of the enormous quantity of residual waste produced daily by the humanity is one of the major challenges of today. One of the solutions is to use biodegradable materials in manufacturing these products $[1,2]$. Wood or cellulose could be suitable materials for this purpose, but their use on an industrial scale leads to excessive exploitation of the forests, with negative effects on climate and environment. On the other hand, the destruction of these materials by burning or putrefaction is pollutant. A viable alternative is the use of regenerative materials obtained from crops or other plants with low pollution potential. Starch is one of the most promising materials for this purpose, because it can be easily obtained at low cost from corn, potatoes, or other vegetables and can be fully recycled without any toxic residues [3-5]. However, starch in its natural state has low mechanical properties and low resistance to water and cannot be used for packaging. Improvement of its qualities can be achieved by combination with glycerol, which acts as a plasticizer. Previously, we obtained new materials by thermal extrusion of different proportions of water, starch, and glycerol $[6,7]$. The samples obtained this way are less soluble in water and have enhanced mechanical properties compared with the initial component. Rheological investigation of these samples show specific flow behavior depending on shear stress and temperature [8]. On a microscopic scale, the NMR investigations indicate different mechanisms of relaxation of the transversal magnetization of the protons depending on temperature and sample composition. These findings were correlated with the new physical structures and local molecular organization induced by the synthesis process [9].

The starch and the pure glycerol, in their initial state, can be easily recycled without pollutant effects by hydration or moderate heating, but the product obtained through the plasticizing process has different physical properties compared with the initial components and exhibits different behavior in the presence of water or when submitted to thermal degradation. Heating is one of the easier ways to destroy the used packaging, but this oxidative process leads to important modification of the physical and chemical properties of the materials. Depending on the temperature and duration of the heating we can assist to modification of the organization of 
TABLE 1: The composition of samples.

\begin{tabular}{lccccc}
\hline Sample & Starch [\%] & Glycerol [\%] & Water [\%] & Starch/Glycerol ratio & Starch/water ratio \\
\hline P1 & 78 & 19.5 & 2.5 & 4 & 31.2 \\
P2 & 72 & 18 & 10 & 4 & 7.2 \\
P3 & 68 & 17 & 15 & 4 & 4.5 \\
\hline
\end{tabular}

the matter (crystallization or molecular rearrangement), or modifications on molecular level (oxidation, chemical bond destruction, and decomposition). Awareness and knowledge of these modifications are crucial for the recycling process and demand investigation employing adequate methods. $\mathrm{XRD}$ is an appropriate technique to investigate the local organization of such materials. In this work, we performed structural investigation of the components in their pure state and of the samples with different initial composition, all submitted to different heating processes. The experimental data were correlated with the modifications of local order induced by the heating.

\section{Materials and Methods}

We prepared samples with different content of starch, glycerol, and water, labeled P1-P3. The initial components were corn starch with $21 \%$ amylose, $10.76 \%$ water content, particle sizes between 2.3 and $37.3 \mu \mathrm{m}$ and density $0.561 \mathrm{~g} / \mathrm{cm}^{3}$; glycerol with $99.5 \%$ purity and density of $1.262 \mathrm{~g} / \mathrm{cm}^{3}$; and distilled water. The composition of samples is shown in Table 1. Previous publications have shown that concentrations of starch higher than $68 \%$ produce sample composition with better results in mechanical properties [10]. These samples were previously investigated by NMR and IR methods [7]. The components were mixed for 30 minutes at room temperature until complete homogenization.

For the samples preparation, we used a corotating twinscrew extruder Collin ZK 25 with controlled gradient temperatures.

The temperatures along the extruder, from the feed zone to the die, are: $30,50,100,130,140^{\circ} \mathrm{C}$ and the rotation speed was $220 \mathrm{rot} / \mathrm{min}$. Following preparation, the samples were kept for 24 hours at room temperature, after which a series of samples were heated for 2 hours at $80^{\circ} \mathrm{C}$ and another series for 2 hours at $140^{\circ} \mathrm{C}$. We selected the first temperature, $80^{\circ} \mathrm{C}$, below the maximum temperature of processing, and another one at the maximum temperature of processing, $140^{\circ} \mathrm{C}$. Visual observation of samples heated at $80^{\circ} \mathrm{C}$ indicates no apparent changes of color and no degradation by burning. We chose this temperature because DSC investigations, reported in literature, performed on similar starch-water gels, indicate thermal transitions around $70-80^{\circ} \mathrm{C}$ [11]. Around $140^{\circ} \mathrm{C}$, the samples change color and become highly degraded. Other works have reported that the above $170^{\circ} \mathrm{C}$ amylose structure transformation can be observed [12]. This was a reason to choose a temperature value below the temperature of total degradation. The XRD measurements were performed with Brucker X-ray diffractometer with $\mathrm{Cu} \operatorname{K} \alpha(\lambda=0,154 \mathrm{~nm})$ at $45 \mathrm{KV}$ and $40 \mathrm{~mA}$. The $2 \theta$ range of $10^{\circ}-90^{\circ}$ was recorded with $0.1^{\circ}$ resolution.

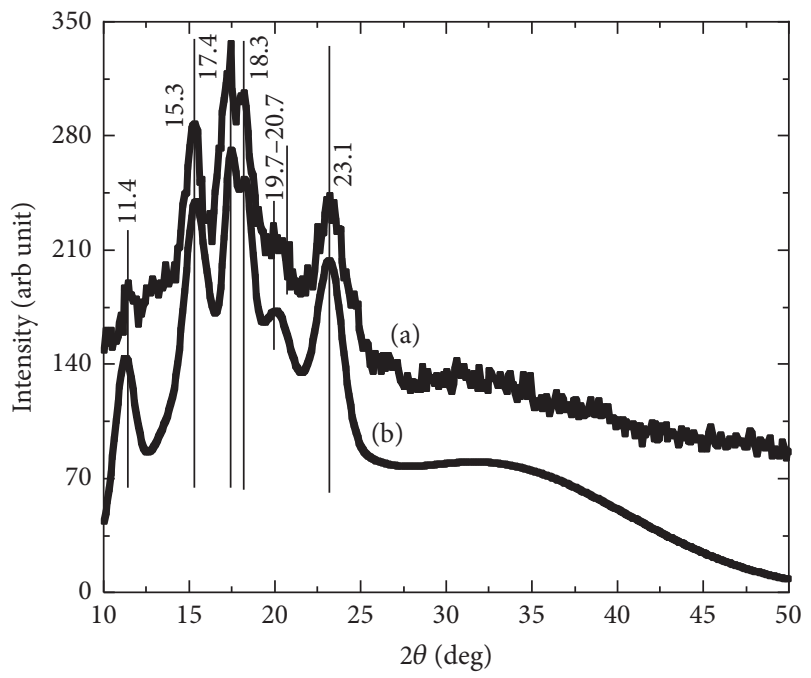

FIGURE 1: The diffractogram of pure starch before heating (a), and the simulation of the main peaks (b). The graphs were separated on the vertical axis by 50 arb unit for better visualization.

\section{Results and Discussion}

Starch is a semicrystalline material which contains both the crystalline and amorphous phases, determined by its principal components, the amylose and the amylopectin. The amylose has a linear structure, which produces the crystalline region of the starch, whereas the amylopectin has a branched structure which is responsible for the amorphous phase of the starch [13-15]. The existence of two phases is confirmed by the aspect of the XRD spectrum before the heating. This spectrum is characterized by a broad region between $10^{\circ}$ and $27^{\circ}$ with some distinctive peaks (Figure 1).

The main peaks are observed at $2 \theta=11.4^{\circ}, 15.3^{\circ}, 17.4^{\circ}$, $18.3^{\circ}$, and $23.1^{\circ}$. A broad peak with low intensity is observed between $19.7^{\circ}$ and $20.7^{\circ}$. Similar results were reported by Holder for pure corn starch and waxy corn starch gels [16]. They have found a broad XRD signal between 10 and 30 degrees with peaks at 17 and 19.5 degrees. Other XRD investigations with similar results were reported by Kim et al. for rice starch and rice starch gels [17]. The slight difference between our data and the articles cited above is due to the ratio amylose/amylopectin, determined by different starch provenience: corn in our case, corn and rice in the above references. Quantitative analysis of the ordered structure can be done after simulation of each peak of the spectrum. The main peaks were simulated with Gaussian function $f(\Theta)$ centered on the diffraction angle $2 \theta$, using Kaleidagraph software:

$$
f(\Theta)=A \cdot \exp \left(-(\beta \cdot(\Theta-2 \theta))^{2}\right) .
$$


TABLE 2: Parameters of the XRD spectrum of the starch in initial state.

\begin{tabular}{lccccc}
\hline $2 \theta[\mathrm{deg}]$ & $A[\mathrm{a} . \mathrm{u}]$ & $\beta[\mathrm{deg}]$ & $d[\AA]$ & $S_{2 \theta}[\mathrm{a} . \mathrm{u}]$ & 125 \\
\\
\hline 11.4 & 90 & 1.3 & 6.9 & 141 & $S_{2 \theta} / S_{\text {tot }}[\%]$ \\
15.3 & 100 & 1.3 & 5.2 & 1479 & 3.1 \\
17 large & 145 & 9.8 & 4.7 & 93 & 33.5 \\
17.4 & 105 & 0.8 & 4.6 & 55 & 2.1 \\
18.3 & 85 & 0.9 & 4.3 & 35 & 1.2 \\
$19.7-20.7$ & 25 & 1.3 & 4.0 & 176 & 0.8 \\
23.1 & 100 & 1.7 & 3.4 & 1664 & 3.9 \\
32 large & 80 & 20.6 & 2.5 & & 37.7 \\
\hline
\end{tabular}

$\Theta$ is the independent variable of the fit. The parameters amplitude $A$ and the half line width $\beta$ of the function were adjusted until a better fit of the experimental data was obtained. These parameters are presented in Table 2 and the simulated spectrum in Figure 1. The narrow peaks are determined by the ordered alignment of the linear parts of the amylose. These structures behave like the crystalline planes of solid crystal (when they are investigated by X-rays). The characteristic interplanar distance $d$ is given by the Bragg equation:

$$
d=\frac{k \cdot \lambda}{2 \sin \theta}
$$

where $k$ is the diffraction order and $2 \theta$ is the diffraction angle [18]. The area $S$ under the diffraction peak is proportional with the concentration of the ordered domains in the sample and the width of the signal is correlated with the size of the ordered domains [19].

The ratio between the area of a given peak and the area of the entire spectrum, $S_{2 \theta} / S_{\text {tot }}$, is shown in Table 2. From this table, we can see that the ordered domains represent small fractions of the sample. The amorphous domains are dominant $\left(33.5 \%\right.$ for the large peak at $2 \theta=17^{\circ}$ and $37.7 \%$ for the large peak at $2 \theta=32^{\circ}$ ).

In the next stage of the investigation, a sample of pure starch was heated for 2 hours at $80^{\circ} \mathrm{C}$ and a second one was heated for 2 hours at $140^{\circ} \mathrm{C}$. The XRD spectra of samples degraded at $80^{\circ} \mathrm{C}$ and $140^{\circ} \mathrm{C}$ are almost similar, but they differ from the spectrum of the initial starch (Figure 2). The noise effect was reduced by smoothing the experimental data using Kaleidagraph software and a smoothing factor of $1 \%$. The shadow line represents the experimental data as recorded, and the solid line represents the result of the smoothing. In our quantitative analysis, we considered the smoothened data. We used the same quantity of sample, same conditions of exposure, the same number of scans, and the same parameters of the recording of spectra in order to be able to make quantitative comparison between the initial and heated samples. For a given mass of substance, the heated samples contain a reduced proportion of crystalline phase compared with the initial sample. For this reason, the spectra of these samples are rather noisy.

During the heating, the ordered arrangement of the linear parts of the amylose is perturbed, and the branching points of the amylopectin are broken. The result is the degradation

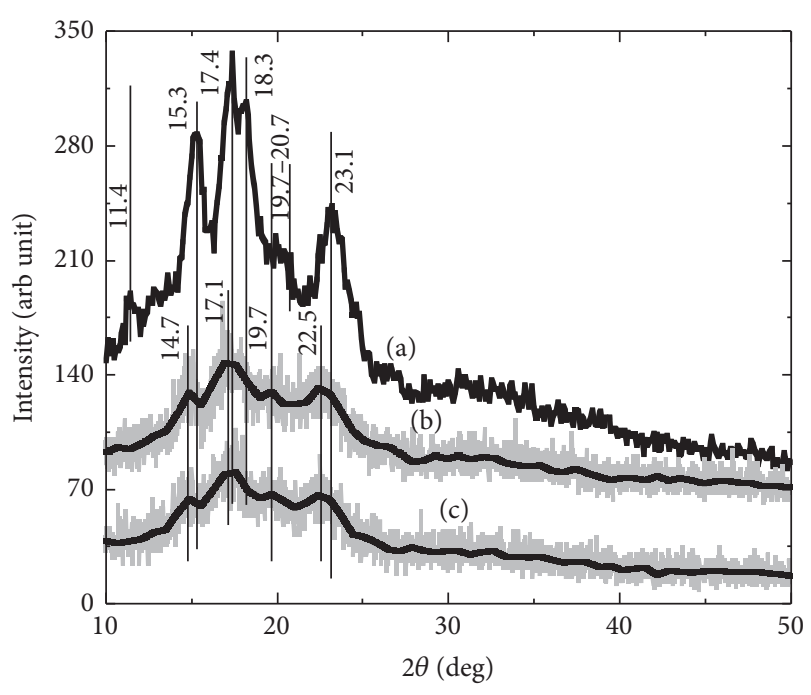

FIgURE 2: The diffractogram of the starch before heating (a), after 2 hours of heating at $80^{\circ} \mathrm{C}(\mathrm{b})$, and after 2 hours of heating at $140^{\circ} \mathrm{C}$ (c). The shadow lines represent the experimental data as recorded and the solid lines represent the data after smoothing.

of the ordered phase and the extension of the amorphous phase [20]. Heating the samples induces the increase of the local mobility of molecules, with possible effect in the size reduction of crystalline granules, disentanglement of the chains, and even the scission of some polymeric chains. Reduction of the crystallinity of starch granules at high temperatures has been previously reported by Jenkins and Donald, 1998; Le Bail et al., 1999; Svensson and Eliasson, 1995 [21-23]. As the granule structure becomes increasingly disrupted at higher temperatures, more starch chains, especially amylopectin, could be disentangled, resulting in decreasing of the local order. Decrease of the intensity after heating was also observed for pure starch by Joanna Wojtasz et al. [5]. Reduction of the crystallinity is correlated with the reduction of the intensities of the peaks.

The main structural modifications of the starch appear after the heating at $80^{\circ} \mathrm{C}$. The heating at $140^{\circ} \mathrm{C}$ produces smaller effects compared with the first heating at $80^{\circ} \mathrm{C}$. For our discussion, we analyzed the spectrum of starch heated at $140^{\circ} \mathrm{C}$. In this spectrum, the intensities of some peaks are reduced and some peaks shift slowly compared with the pure starch (Figure 2). For instance, the peaks at $2 \theta=11.4^{\circ}$ and $18.3^{\circ}$ of initial starch disappear in the spectrum of degraded 
TABLE 3: Parameters of XRD spectrum of the starch heated 2 hours at $140^{\circ} \mathrm{C}$.

\begin{tabular}{lccccc}
\hline $2 \theta[\mathrm{deg}]$ & $A[\mathrm{a} . \mathrm{u}]$ & $\beta[\mathrm{deg}]$ & $d[\AA]$ & $S_{2 \theta}[\mathrm{a} . \mathrm{u}]$ & $S_{2 \theta} / S_{\text {tot }}[\%]$ \\
\hline 14.7 & 10 & 1.3 & 5.4 & 14 & 0.9 \\
17 large & 60 & 10.7 & 4.7 & 611 & 40 \\
17.1 & 15 & 1 & 4.6 & 63 & 4.1 \\
19.7 & 5 & 0.9 & 4.0 & 4 & 0.3 \\
22.5 & 20 & 1.8 & 3.5 & 35 & 2.3 \\
32 large & 30 & 19.4 & 2.5 & 624 & 41 \\
\hline
\end{tabular}

starch. The peak at $2 \theta=15.3^{\circ}$ shifts to $14.7^{\circ}$, the peak $2 \theta=$ $23.1^{\circ}$ shifts to $22.5^{\circ}$, the peaks at $2 \theta=17.4^{\circ}$, and $18.3^{\circ}$ merge into a large peak at $17.1^{\circ}$. The large peak $2 \theta=19.7^{\circ}-20.7^{\circ}$ shifts to $19.7^{\circ}$. Quantitative analysis was done after simulation of the mains peaks of the spectrum using the same procedure as in the case of pure starch before heating. The parameters of the fit for the sample heated for 2 hours at $140^{\circ} \mathrm{C}$ are presented in Table 3. The shift of the peaks towards small diffraction angles means increase of the interplanar diffraction distance.

The particularities of starch structure are determined by the linkage of the amylose and amylopectin subunits. The amylose subunits are linked mostly $\alpha-(1 \rightarrow 4)$ whereas the amylopectin has subunits linked both $\alpha-(1 \rightarrow 4)$ and $\alpha-(1 \rightarrow 6)$, with about $95 \%$ of the glycosidic bonds being $\alpha-(1 \rightarrow 4)$ linkages and $5 \%$ being $\alpha-(1 \rightarrow 6)$. The $\alpha-(1 \rightarrow 6)$ linkages in amylopectin cause the polymer to be highly branched [24]. The amylopectin molecular chains form parallel, dense, lefthanded double helices with six glucose residues per turn [25]. The two helices are linked in a double helix by an $\alpha-1,6$ branch point. The double helices can be aligned in two different crystalline lattices: the A-type polymorph [26], which is dense, and the B-type polymorph [27], less dense. Increasing of the thermal agitation during the heating could be favorable to the alignment of starch molecules on the less dense structure, which could explain the small shift of the XRD peaks of pure starch towards small angles for heated samples.

Another effect is the decrease of the ratio between the area of narrow peaks and the area of the entire spectrum (Table 3). That indicates a reduction of the amount of the ordered domains. On the other hand, the largest peaks at $2 \theta=17^{\circ}$ and $2 \theta=32^{\circ}$ have greater ratio $S_{2 \theta} / S_{\text {tot }}$ in the degraded sample, $40 \%$ respectively $41 \%$, compared with $33.5 \%$ and $37.7 \%$ of the pure starch (Table 3). That means extension of the amorphous domain.

The XRD diffractograms of samples P1-P3, before heating, show different degrees of local ordering depending on the initial composition. In solid starch, most of the molecules are densely packed in an ordered phase and only a small part of the polymer is mobile, in amorphous state [25]. Parts of the same chain can be in a crystalline state, whereas other parts can be in a disordered state [28]. The amorphous parts of the chains are more accessible to water and can easily form gels. Adding water to solid starch is followed by the swelling of the material with the consequence of reducing the crystallinity. Thus, we can explain the differences observed between the spectra of solid starch and samples P1-P3.

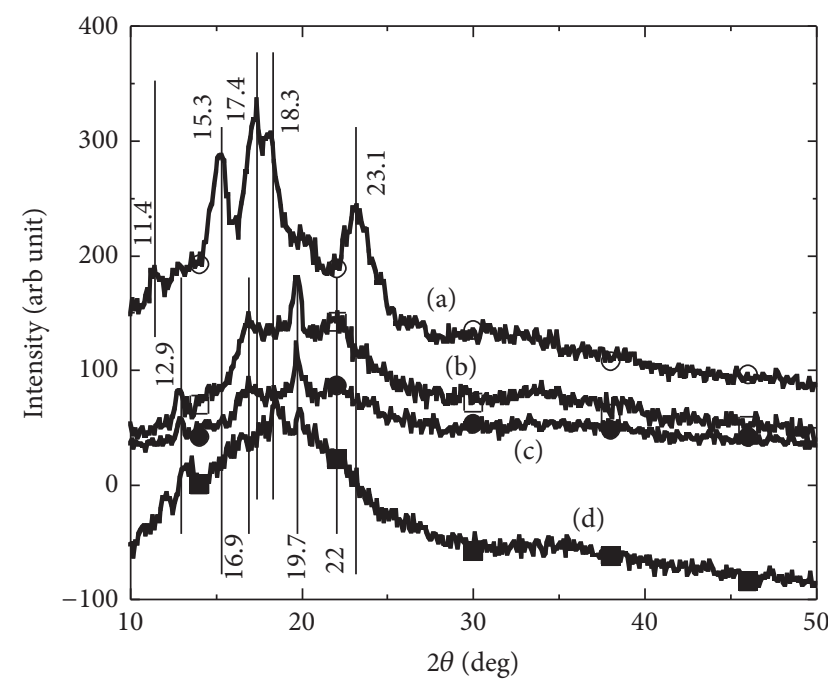

FIGURE 3: The XRD pattern of pure starch (a), sample P1 (b), sample P2 (c), and sample P3 (d) before heating.

As in the case of pure starch, the diffractograms of samples $\mathrm{P} 1$ to $\mathrm{P} 3$ contain a broad region in the domain $10^{\circ}-$ $25^{\circ}$ with some distinctive peaks with intensities depending on the concentration of starch. For instance, in the spectrum of sample P1 we can see small but distinctive peaks at $2 \theta=12.9^{\circ}$, $16.9^{\circ}, 19.7^{\circ}$, and $22^{\circ}$. The intensity of these peaks decreases in the spectrum of sample P2, and they almost disappear in the spectrum of sample P3 (Figure 3). In each of the samples $\mathrm{P} 1-\mathrm{P} 3$ the quantity of starch is decreased, which explains the reduction of the intensities of the narrow peaks. The peak $2 \theta=11.4^{\circ}$ of pure starch is shifted to $2 \theta=12.9^{\circ}$ for P2 and P3.

In the presence of water, the mobility of starch molecules increases allowing better packing, better arrangement of branched structure of amylopectin, and thus a more compact packaging of molecules inside the ordered domains. This supposition is in agreement with the model proposed by Kainuma and French, suggesting that glucose polymers form double helices upon addition of water [29]. The effect is the decrease of interplanar distances $[30,31]$. The intense peaks at $2 \theta=15.3^{\circ}, 17.4^{\circ}$, and $18.3^{\circ}$ of pure starch are missing in the spectra of samples $\mathrm{P} 1-\mathrm{P} 3$, but we can see a peak at $2 \theta=16.9^{\circ}$. The large peak between $19.7^{\circ}$ and $20.7^{\circ}$ of pure starch becomes narrow and can be seen at $19.7^{\circ}$ in the spectra of samples P1 to P3. The peak at $23.1^{\circ}$ shifts to $22^{\circ}$ in the spectra of P1 and $\mathrm{P} 2$ and it is absent for sample P3. This behavior indicates a reduction of the ordered phase when the concentration of starch decreases.

The effect of thermal degradation was also observed for samples P1-P3. These samples were heated for 2 hours at $80^{\circ} \mathrm{C}$ and $140^{\circ} \mathrm{C}$. For sample $\mathrm{P} 1$, heated at $80^{\circ} \mathrm{C}$, we can see peaks at $12.9^{\circ}, 16.9^{\circ}, 19.7^{\circ}, 22^{\circ}$, and $32^{\circ}$, similar to the initial sample before thermal degradation (Figure 4, curve (b)). However, their intensities and their areas are substantially reduced. That means a decrease of the amount of ordered structure associated with these peaks. At $140^{\circ} \mathrm{C}$, the intensity of the peaks diminishes again, the peak at $12.9^{\circ}$ become broad, the peak at $19.7^{\circ}$ shifts to $20.5^{\circ}$, and the peak at $32^{\circ}$ is missing 


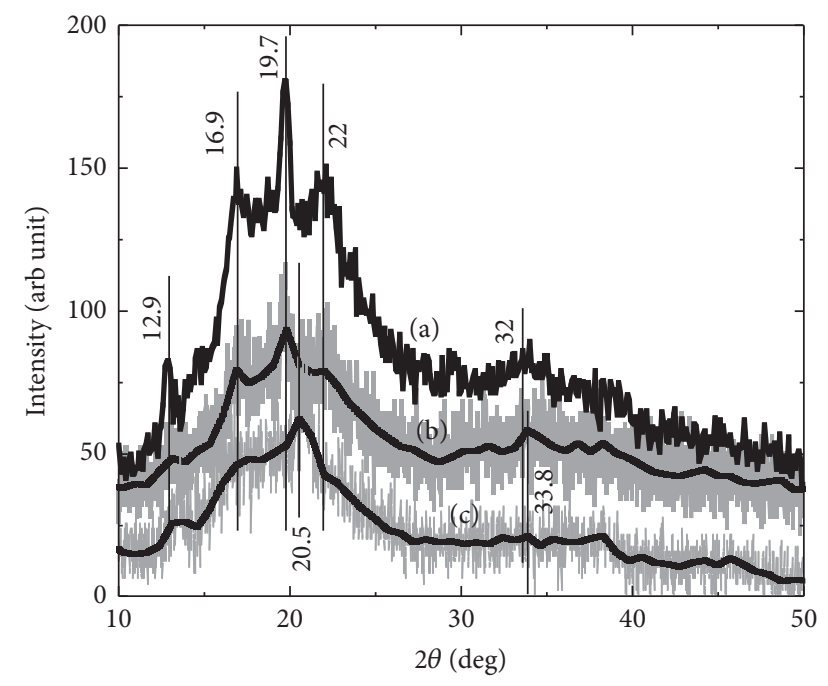

FIGURE 4: XRD pattern of sample P1 as obtained (a), after 2 hours of heating at $80^{\circ} \mathrm{C}(\mathrm{b})$, and after 2 hours of heating at $140^{\circ} \mathrm{C}$ (c). The shadow lines represent the experimental data as recorded and the solid lines represent the data after smoothing.

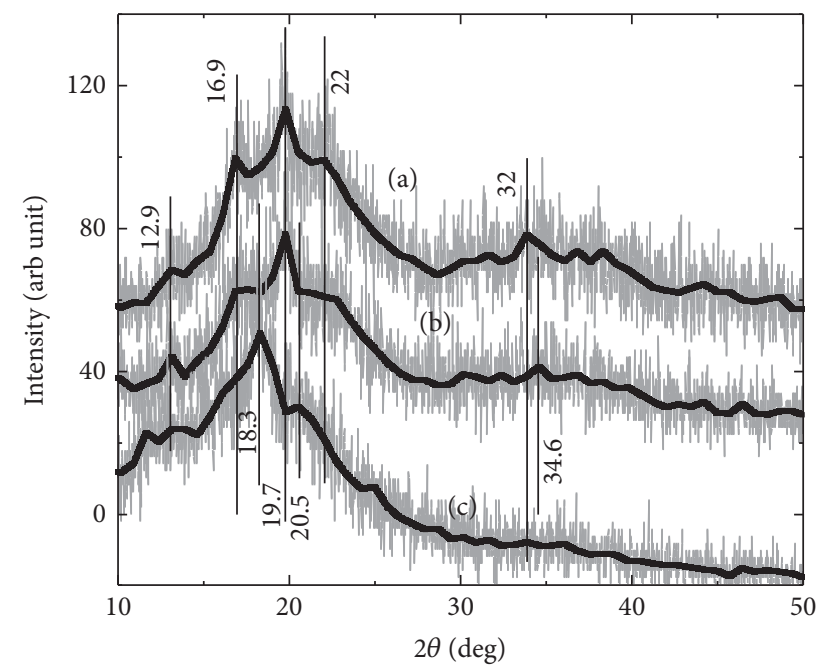

FIGURE 5: The XRD diffractograms of samples P1-P3 heated 2 hours at $80^{\circ} \mathrm{C}$ : (a) sample $\mathrm{P} 1$, (b) sample $\mathrm{P} 2$, and (c) sample P3. The shadow lines represent the experimental data as recorded and the solid lines represent the data after smoothing.

(Figure 4 curve (c)). That shows further decrease of the amount of the ordered phase and increase of the amount of the amorphous phase when the temperature increases. Similar behavior can be seen for samples P2 and P3, but the degradation is more pronounced. The spectra become noisier and the peaks can be difficult to distinguish. For sample P2 heated for 2 hours at $80^{\circ} \mathrm{C}$, we can see peaks at $12.9^{\circ}, 16.9^{\circ}$, and $19.7^{\circ}$, similar to sample P1 (Figure 5 curve (b)). The peak at $22^{\circ}$ is missing and the peak at $32^{\circ}$ shifts to $33.8^{\circ}$. For sample $\mathrm{P} 3$, the entire spectrum is broad with peaks at $18.3^{\circ}$ and $20.5^{\circ}$ (Figure 5 curve (c)). The ordered structure for this sample at this temperature is strongly affected. The sample is almost entirely amorphous. The concentration of starch decreases in samples P1-P3 and our results show that the degradation of the ordered phase is more pronounced at low concentration of starch.

\section{Conclusion}

The effects of thermal degradation of some starch based systems were investigated by XRD. Three systems with different starch concentration were obtained by extrusion technique using glycerol as plasticizer. The systems were investigated before and after thermal degradation. The XRD measurements for pure starch, before heating, indicate the existence of two phases: an ordered one and an amorphous one. The ordered phase is determined mainly by the amylose and branching points of amylopectin, while the amorphous phase is associated with the short-branched chains of amylopectin. Thermal heating at $80^{\circ} \mathrm{C}$ is followed by partial destruction of its ordered structure. The ordered phase is almost completely destroyed after heating at $140^{\circ} \mathrm{C}$.

The ordered phase is also detected for samples P1-P3, but its concentration depends on the initial composition. Samples with high concentration of starch have large regions with ordered structure. After 2 hours of heating at $80^{\circ} \mathrm{C}$, most of the ordered phase is destroyed. The degradation continues with temperature increased to $140^{\circ} \mathrm{C}$. The degradation of the ordered structure is more pronounced in samples with low content of starch. Heated at $140^{\circ} \mathrm{C}$, these samples become almost entirely amorphous.

The XRD investigations demonstrate the role of starch in the thermal stability and local ordered organization of these samples.

\section{Competing Interests}

The authors declare that there is no conflict of interests regarding the publication of the paper.

\section{Acknowledgments}

This work was supported by CNCSIS-UEFISCDI, Projects nos. PN II-IDEI code 284/2011 and NUCLEU-PN 162402 02 .

\section{References}

[1] C. Bastioli, "Global status of the production of biobased packaging materials," in Proceedings of the Food Biopak Conference, pp. 2-7, Denmark, Copenhagen, August 2000.

[2] J. Gómez-Estaca, R. Gavara, R. Catalá, and P. HernándezMuñoz, "The potential of proteins for producing food packaging materials: a review," Packaging Technology and Science, vol. 29, no. 4-5, pp. 203-224, 2016.

[3] M. Mitrus and L. Moscicki, "Extrusion-cooking of starch protective loose-fill foams," Chemical Engineering Research and Design, vol. 92, no. 4, pp. 778-783, 2014.

[4] F. Xie, P. J. Halley, and L. Avérous, "Rheology to understand and optimize processibility, structures and properties of starch polymeric materials," Progress in Polymer Science, vol. 37, no. 4, pp. 595-623, 2012. 
[5] J. Wojtasz, J. Carlstedt, P. Fyhr, and V. Kocherbitov, "Hydration and swelling of amorphous cross-linked starch microspheres," Carbohydrate Polymers, vol. 135, pp. 225-233, 2016.

[6] N. Cioica, R. Fechete, R. Chelcea et al., "Water absorption and degradation of packages based on native corn starch with plasticizers," Studia Universitatis Babes-Bolyai Chemia, vol. 60, no. 1, pp. 45-55, 2015.

[7] N. Cioica, R. Fechete, C. Cota, E. M. Nagy, L. David, and O. Cozar, "NMR relaxation investigation of the native corn starch structure with plasticizers," Journal of Molecular Structure, vol. 1044, pp. 128-133, 2013.

[8] E. M. Nagy, M. Todica, C. Cota, C. V. Pop, N. Cioica, and O. Cozar, "Water degradation effect on some starch-based plastics," in Proceedings of the 43rd International Symposium on Agricultural Engineering 'Actual Tasks on Agricultural Engineering', pp. 755-762, Opatija, Croatia, 2015.

[9] C. Coța, N. Cioica, C. Filip et al., "Spectroscopic investigation of the constituent components effect on the biodegradable package characteristics," in Proceedings of the AIP Conference, Cluj-Napoca, Romania, 2015.

[10] N. Cioica, R. Fechete, C. Cota, E. M. Nagy, O. Cozar, and C. V. Pop, "Structural changes of the corn starch from Romania used to make biodegradable packaging," in Proceedings of the Symposium Actual Tasks on Agricultural Engineering, pp. 398404, Opatija, Croatia, 2013.

[11] K. Tananuwong and D. S. Reid, "DSC and NMR relaxation studies of starch-water interactions during gelatinization," Carbohydrate Polymers, vol. 58, no. 3, pp. 345-358, 2004.

[12] J. A. Creek, G. R. Ziegler, and J. Runt, "Amylose crystallization from concentrated aqueous solution," Biomacromolecules, vol. 7, no. 3, pp. 761-770, 2006.

[13] H. Liu, L. Yu, F. Xie, and L. Chen, "Gelatinization of cornstarch with different amylose/amylopectin content," Carbohydrate Polymers, vol. 65, no. 3, pp. 357-363, 2006.

[14] J. Jane, "Current understanding on starch granule structures," Journal of Applied Glycoscience, vol. 53, no. 3, pp. 205-213, 2006.

[15] R. F. Tester, J. Karkalas, and X. Qi, "Starch-composition, fine structure and architecture," Journal of Cereal Science, vol. 39, no. 2, pp. 151-165, 2004.

[16] B. H. Holder, Characterization of starch by vibrational spectroscopy [Dissertations \& Theses in Food Science and Technology], University of Nebraska-Lincoln, Lincoln, Neb, USA, 2012.

[17] J.-O. Kim, W.-S. Kim, and M.-S. Shin, "A comparative study on retrogradation of rice starch gels by DSC, X-ray and $\alpha$-amylase methods," Starch/Staerke, vol. 49, no. 2, pp. 71-75, 1997.

[18] M. Todica, V. Simon, T. Stefan, D. L. Trandafir, and I. Balasz, "Spectroscopic investigation of gamma irradiated PAA-graphite membranes," Indian Journal of Pure and Applied Physics, vol. 53, no. 6, pp. 359-366, 2015.

[19] B. Stuart, Polymer Analysis, John Wiley \& Sons, Chichester, UK, 2002.

[20] H. Liu, F. Xie, L. Yu, L. Chen, and L. Li, "Thermal processing of starch-based polymers," Progress in Polymer Science, vol. 34, no. 12, pp. 1348-1368, 2009.

[21] P. J. Jenkins and A. M. Donald, "Gelatinisation of starch: a combined SAXS/WAXS/DSC and SANS study," Carbohydrate Research, vol. 308, no. 1-2, pp. 133-147, 1998.

[22] P. Le Bail, H. Bizot, M. Ollivon, G. Keller, C. Bourgaux, and A. Buléon, "Monitoring the crystallization of amylose-lipid complexes during maize starch melting by synchrotron X-ray diffraction," Biopolymers, vol. 50, no. 1, pp. 99-110, 1999.
[23] E. Svensson and A.-C. Eliasson, "Crystalline changes in native wheat and potato starches at intermediate water levels during gelatinization," Carbohydrate Polymers, vol. 26, no. 3, pp. 171176, 1995.

[24] A. A. Karim, M. H. Norziah, and C. C. Seow, "Methods for the study of starch retrogradation," Food Chemistry, vol. 71, no. 1, pp. 9-36, 2000.

[25] F. H. Larsen, A. Blennow, and S. B. Engelsen, "Starch granule hydration-a MAS NMR investigation," Food Biophysics, vol. 3, no. 1, pp. 25-32, 2008.

[26] A. Imberty, H. Chanzy, S. Pérez, A. Bulèon, and V. Tran, "The double-helical nature of the crystalline part of A-starch," Journal of Molecular Biology, vol. 201, no. 2, pp. 365-378, 1988.

[27] A. Imberty and S. Pérez, "A revisit to the three-dimensional structure of B-type starch," Biopolymers, vol. 27, no. 8, pp. 12051221, 1988.

[28] H. J. Thiewes and P. A. M. Steeneken, "The glass transition and the sub- $\mathrm{T}_{\mathrm{g}}$ endotherm of amorphous and native potato starch at low moisture content," Carbohydrate Polymers, vol. 32, no. 2, pp. 123-130, 1997.

[29] K. Kainuma and D. French, "Naegeli amylodextrin and its relationship to starch granule structure. II. Role of water in crystallization of B-starch," Biopolymers, vol. 11, no. 11, pp. 22412250, 1972.

[30] M. Todica, T. Stefan, D. Trandafir, and S. Simon, "ESR and XRD investigation of effects induced by gamma radiation on PVA$\mathrm{TiO}_{2}$ membranes," Central European Journal of Physics, vol. 11, no. 7, pp. 928-935, 2013.

[31] V. M.-F. Lai, S. Lu, and C.-Y. Lii, "Molecular characteristics influencing retrogradation kinetics of rice amylopectins," Cereal Chemistry, vol. 77, no. 3, pp. 272-278, 2000. 

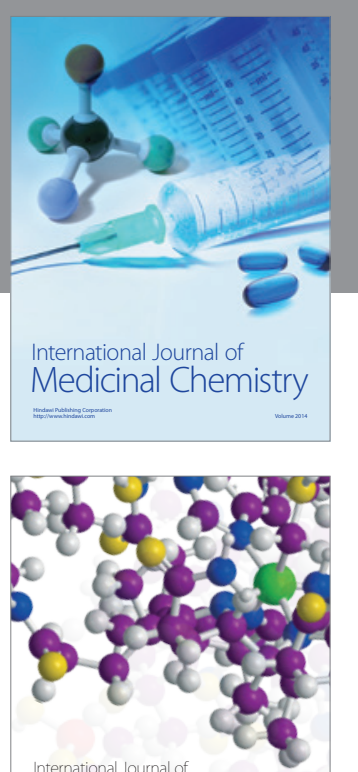

Carbohydrate Chemistry

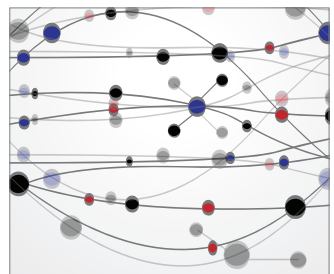

The Scientific World Journal
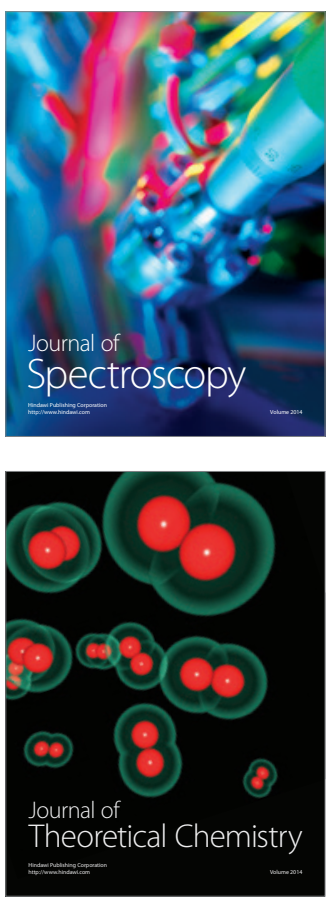
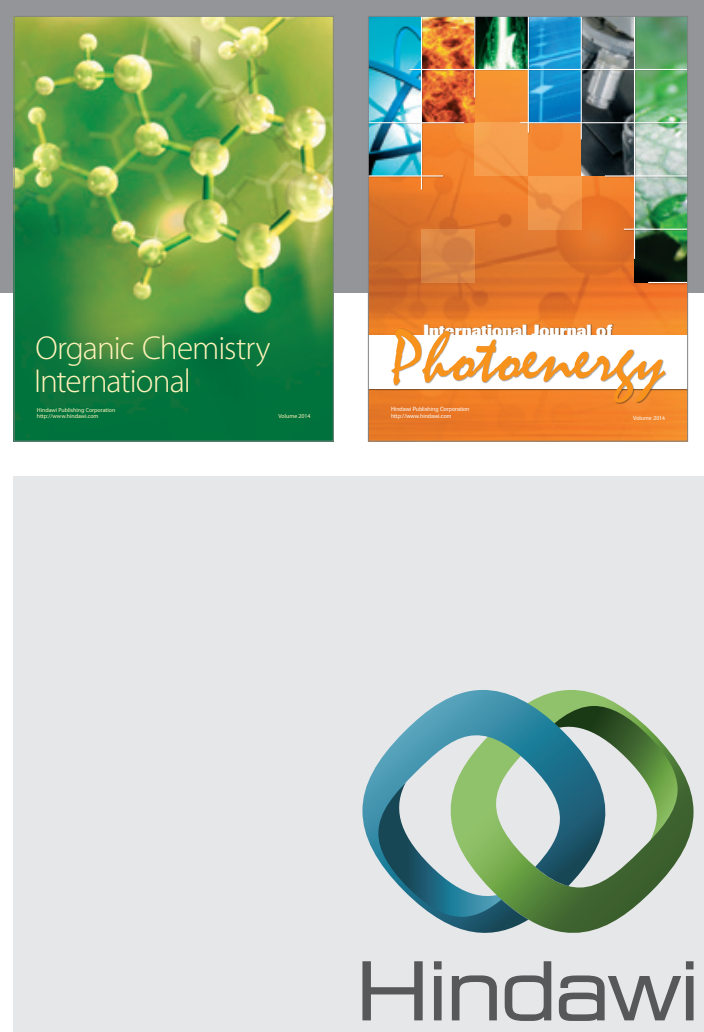

Submit your manuscripts at

http://www.hindawi.com

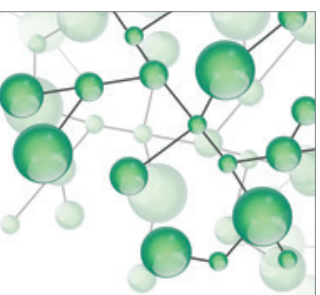

International Journal of

Inorganic Chemistry

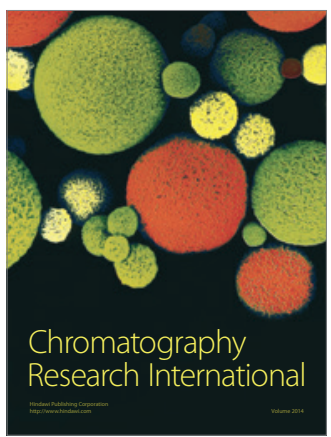

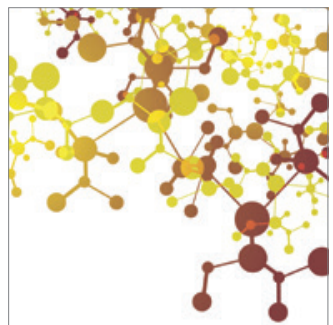

Applied Chemistry
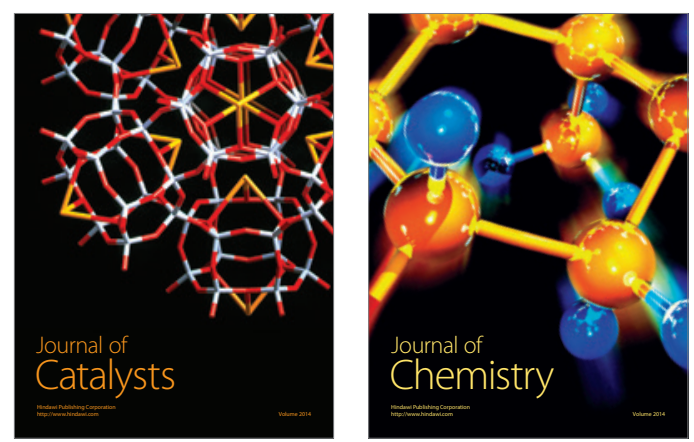
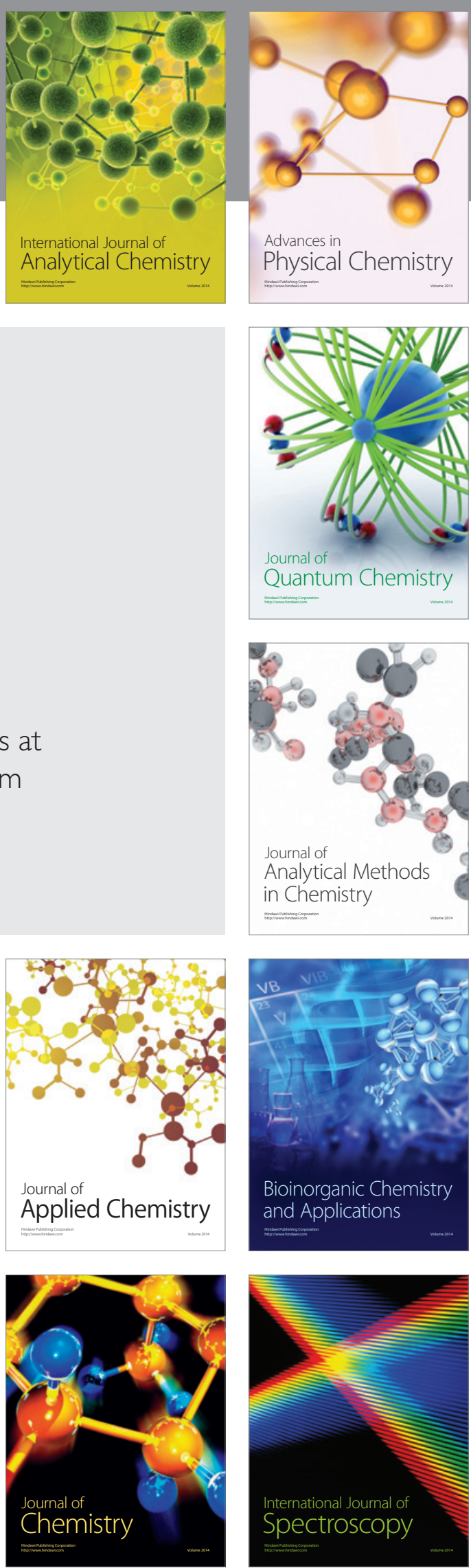